\title{
Do Social Networks Really Matter in Contentious Politics?
}

Florence Passy and Gian-Andrea Monsch

University of Lausanne

For the special issue of Social Movement Studies

'Social Networks and Social Movements'

Editors: John Krinsky and Nick Crossley

October 2012

Word count: 12'780 


\begin{abstract}
A considerable number of studies in the social movement literature stress that social networks are a key factor for those participating in political protest. However, since empirical evidence does not universally support this thesis, we propose to examine three core questions. Do networks really matter for participants in political protest? Are social networks important for all types of protest? Finally, what are social networks and in which ways are they important? By answering these questions this paper aims to provide three contributions to social movement literature: first, we want to put networks in their place and not reifying their influence on participation processes; second, we describe and explain variations of networks influence on protest participation; third, to pursue the theoretical reflection initiated by Kitts, McAdam, and Passy on the specification of network effect on contentious participation, that is, to disentangle the different processes at stake. Many scholars argue for empirical works analyzing the link between networks and cognition, but this remains a pious wish. Here, we propose to systematically examine the effect of social interactions on activists' cognitive toolkit.
\end{abstract}


'Conversation in general shapes social life by altering individual and collective understandings, by creating and transforming social ties, by generating cultural materials that are then available for subsequent social interchange, and by establishing, obliterating, or shifting commitments on the part of participants.' Charles Tilly (1998: 507)1.

Lisa, a thirty-two year old activist, spends hours on legal work to defend asylum seekers ${ }^{2}$. She participates in many contentious groups claiming for a fairer migration and asylum policy in Switzerland. Before joining the migrants' rights protest, Lisa studied at the University of Lausanne where she was involved in student groups protesting against the decision of the cantonal authorities to increase students' taxes. Lisa perceived the powerholder's decision as extremely unjust. She was not personally touched by this measure, as her parents had a fairly high economic standard and she had almost finished her studies. Nonetheless, as a student she identified with the protestors and offered her active support to the contention. A few activists convinced her that by uniting together they could win and reverse the cantonal decision. For Lisa, this period was rich in political disputes. She also built a dense network of politically committed friends that bonded her to other contentious sites. She joined the squatters' milieu where she enjoyed discussions about free-cultural spaces, participatory democracy and horizontal forms of power thus making her conscious of the importance of political associations. She learned a lot from this milieu and developed a deep consciousness that being politically active is one the most important aspects of living in a democracy, in order to resist individualism, and to bring about social changes.

A few years later, through the intermediary of two friends from the student and squatters' movements, Lisa joined the association Legal Help Services for Exiled People. She developed a strong interest in questions relating to migration during her extensive travels around the world. Lisa was rightly indignant that she could travel and settle almost everywhere, while migrants arriving in Europe could not lawfully settle, or only as illegal immigrants. The absence of equality between her situation and those of migrants led her to develop a deep sense of injustice, 'a deep revolt'. Her reading on migratory problems only served to reinforce her moral indignation. Lisa's deep sense of injustice on those social issues and her conviction that protest action is efficient as a means of challenging power-holders persuaded her to participate in the defense of migrants' rights.

Is Lisa's commitment a typical story of protest activism in which social networks seem to be a key factor? Her story reveals that networks played an important role through two main social mechanisms. First, they intervened to connect Lisa from one protest site to another. Second, they were a crucial element in developing meanings through dense conversational interactions enabling her to take an active part in different contentious fields. In this respect, Lisa's story equates well with the Charles Tilly quotation. Conversations alter individual understanding and generate cultural material that is then

\footnotetext{
${ }^{1}$ We thank Mario Diani, Doug McAdam, and the anonymous reviewers of Social Movement Studies for their helpful critiques on earlier drafts of this article.

${ }^{2}$ Lisa is one among the 40 activists with whom we collected life history and in-depth interviews (see Method and data).
} 
available for newer social interchange, by establishing, obliterating and shifting commitment on the part of participants of such networks.

Lisa's story, like an impressive number of studies in the social movement literature, reveals that networks are a key facilitating factor for participating in protest. But do networks really matter in contentious politics? In fact, empirical evidence does not universally support the thesis of a link between networks and participation in protest politics (Jasper and Poulsen 1993). In reality, networks seem to be just one factor among others (Jasper 1997). Lisa's story highlights this controversy. Her moral indignation toward migrants' fate was not constructed through social interactions but through her travelling experience all around the world. Similarly, McAdam (1988) found that one third of the Freedom Summer volunteers were not embedded in networks, thus providing further evidence of the irrelevance of network processes for many activists. The importance of networks seems to have been overestimated by scholars of social movements. This apparent overestimation incites us to compare more systematically social interactions with other processes at work in order to assess their effective importance in the process of joining contentious action.

These controversial findings raise another question: Are social networks important for all types of protest? In some types of protest, networks seem to constitute a crucial factor (della Porta 1988), while in others their role is less marked (Oliver 1984), or even not noticeable at all (Mullins 1987). Scholars' findings were not always consistent. These inconsistencies arose because variations among types of contentious action have been understudied. Protest actions are diverse by nature, and the effect of social interactions may be decisive in certain contentions but not in others. For instance, they probably play a more important role in the conduct of challenging and risky protest, as in the civil rights movement, or in the violent underground contentions studied by McAdam or della Porta, yet have only a peripheral influence in less demanding protests, such as the animal rights movement, as analyzed by Jasper and Poulsen. Activists are of a diverse nature, too. In protest activity we find some participants, such as Lisa, that are highly involved in protest action but also others who merely support protests by providing them with financial resources. For less demanding forms of activism, social interactions are perhaps less important than in those requiring higher levels of personal commitment. Inconsistent findings urge us to compare types of protest and activism in order to better assess the influence of social networks.

Inconsistencies are also partly due to different conceptualizations of networks by scholars of social movements. This brings us to the last question: What are social networks and in which ways are they important? In the social movements literature, networks are often conceived either in structural terms through their role in connecting prospective activists to a protest opportunity, or in interpretative terms by shaping identity, which is essential in order to become involved in contention. However, connecting and identity-building do not exhaust the range of influence of networks. As Charles Tilly's excerpt stresses, social interactions are conversations that shape individuals' understanding and generate cultural materials. Interactions not only affect a person's identity frame, they also clarify other meanings, such as injustice and agency frames (Gamson 1992). Conversational interactions provide actors with cognitive resources that enable them to become effective 
and committed activists. As we saw in Lisa's story, it was within the flow of discussions and interactions that she developed action frames, such as moral indignation, the perception that protesting collectively brings about social changes, etc. In addition, most scholars do not disentangle a bridging process from an interpretative one. In the abundant literature on networks and participation, only three scholars have tried to disentangle those social processes (Kitts 2000, McAdam 2003, Passy 2003). Moreover, the interpretative process is largely understudied or examined solely through the prism of identity-building. We propose to examine more carefully the importance of social interactions on developing and modifying individuals' cognitive toolkit, and to analyze both bridging and interpretive processes separately in order to specify their respective influence on participation in contentious politics.

The paper aims to provide three contributions to social movement literature. First, we want to put networks in their place, rather than reifying their influence to participation processes. Whereas social interactions seem to constitute a key process facilitating participating in many protest movements, other processes are at work that are sometimes much more effective than social networks. Second, we compare different types of activism in order to understand and explain these variations. Diani (2003) and McAdam (2003) urged social movement scholars to abandon case studies in favor of comparative works in order to avoid reifying the effects of social networks on participation, and to explain the variations at stake. To our knowledge no scholars have undertaken systematic comparisons to explain the varying influence of social networks on participation. Finally, we pursue the theoretical reflection initiated by Kitts, McAdam, and Passy on the specification of network effects on protest participation; that is to disentangle the different processes at work. Here again, many scholars argue for more empirical works analyzing the link between networks and cognition (Diani 2003, McAdam 2003). However, this remains a pious wish. In this article, we place specific emphasis on the interpretative effect of social interactions via networks on activists' cognitive tool-kit.

The remainder of the article is structured as follows: we first briefly discuss the concept of networks and its recent inclusion in social theory, in order to better grasp what networks actually mean. We then review the major findings on networks and contentious participation. This section enables us to pinpoint theoretical shortcomings for which we bring theoretical development and specification. We then respond to our three questions by referring to empirical data. Finally, the paper concludes by suggesting several directions for future research.

\section{From Structure to Meanings and Agency}

In the nineteen nineties, Emirbayer and his colleagues (Emirbayer and Goodwin 1994; Emirbayer 1997; Emirbayer and Mische 1998) emphasized that a 'realist view' of social interactions dominates social science literature ${ }^{3}$. Networks are conceived in either structural or rational terms that leave aside an interpretative view of social interactions. By embracing the 'linguistic turn' in sociology, White (1992) elaborated an interpretative view of networks that conceives them as 'islands of meanings'. For White networks are composed of discourses, stories and meanings; networks themselves are created through

\footnotetext{
${ }^{3}$ In this paper we use networks and social interactions as synonymous.
} 
narratives. This groundbreaking conception of social interactions highlights first that 'discourse is the stuff of social networks', an 'inter-animation of talks and ties' (Mische and White 1998). Second, networks are generated through discourse: 'a tie becomes constituted by story, which defines a social time by its narrative of ties' (White 1992: 67).

This understanding of networks is theoretically interesting for (at least) two main reasons. First, it enables us to better grasp the link between social interactions and an individual's cognitive toolkit. An individual's inner world is filled with worldviews, meanings or cognitions about the world around them. This set of meanings (or an individual's cognitive toolkit) is in part created and transformed by 'conversational interactions'. White's understanding of networks is that, theoretically, they provide a bridge between social interactions and an individual's cognitive map. Thus an individual's cognitive toolkit is continuously enriched and modified by personal experiences, external events, and conversational interactions.

Second, White elaborates a dynamic and agentic view of networks. Individuals are engaged in on-going conversations in their daily life and are involved in multiple and fluid interactions. This flux of interactions entails changes and transformations over time. In this interactive process individuals are not involved passively as in an incubator process, in which the mere location in relational settings shapes individuals' worldviews; instead, they are agents in a communicative process in which they play an active role (Mische 2011). Individuals are in a permanent process of interpretation of their multiple discussions and interactions. They make sense of their multiple communications in their inner-self, adapting and transforming their mental map in an agentic way. Individuals' cognitive toolkits reorganize and modify agentically in the course of actors' multiple interactions. Actors are in on-going conversations with incessant improvisations for acting (Tilly 1998).

This heuristic understanding of networks, focusing on meanings and cognition, enables us to overcome the antinomies between structure and action (Emirbayer and Goodwin 1994; Mische 2011) and is a conception that we theoretically endorse in our understanding of social interactions. However, endorsing an interpretative understanding of social networks, and a dynamic and agentic view of social interactions, does not mean that we regard all of these interactions as being of equal importance. On the contrary, exchanges conducted on a regular basis have a much greater chance of providing actors with cultural meanings and enriching their cognitive toolkit than superficial interactions such as those occurring in an individual's daily life. This conception of networks has at least two consequences. First, only specific types of interaction may shape an actor's cognitive toolkit. Second, not all interactions matter to the same extent for participation in contentious politics.

Parallel to this dynamic and agentic conception of networks we also endorse the agentic understanding of cultural toolkit elaborated by Swidler (1986) in which the individuals' cognitive toolkit enables actors to organize 'strategies of actions'. As individuals store a large amount of cognitions in their minds throughout their lifetime, they inevitably 'know' more than they use. Consequently, individuals selectively use elements from their cognitive toolkit in their interactions. Their cognitive resources do not determine individuals' action, rather action is the result of individuals' constructions, negotiations, 
and improvisations. Actors' cognitive repertoire thus determines the range of options they find available; it delineates what individuals can do empirically ${ }^{4}$.

\section{Networks and Participation in Contentious Politics: What Do We Know?}

In the literature, social movement is conceived as a relational process and not as aggregates of activists or collective actors (Diani 2007). For Diani (forthcoming), social movements are specific modes of coordination for collective action that imply exchanges of resources and definition of boundaries achieved through narratives and identitybuilding. Diani's definition parallels Tilly's (1998) conception of contentious politics, which is composed of on-going conversations between protest actors, between protest actors and power-holders, as well as between activists and their public. Contention is thus made up of relations. Networks are not only essential at the organizational level but also at the level of individuals. Since the nineteen seventies, and in opposition to mass society and social psychologists' accounts, scholars have extensively analyzed the links between networks and contentious participation. What do we know from these numerous studies?

Oberschall (1973) was one of the first authors who showed that clusters of existing organizations are recruited wholesale into new protest movements ('bloc-recruitment'). In the same period, Tilly (1978) stressed that the co-presence in a given population of categorical traits and networks enables individuals to join a specifically selected protest action. Categorical traits facilitate recognition and identity construction, and networks favor exchanges that lead to a mobilization of resources ('catnet'). Numerous studies confirmed the thesis that prior embeddedness in network clusters or enclaves facilitate individuals' participation in protest (della Porta 1988; Diani 1995; Fernandez and McAdam 1988; Gould 1995; Kriesi 1988; Melucci 1989; McAdam 1988; Mische 2003; Passy 2003). These studies postulate that it is not social pressure within enclaves or solidarities that matter, but an identity-building process that facilitates contentious participation. Individuals' affiliation to different enclaves generates shared identity. Thus, 'participatory identities' develop and enable individuals to join specific contentions (Gould 1995; McAdam and Paulsen 1993). Parallel to these studies, other scholars emphasized that personal bonds with leaders or influential members encourage participation in protest action. For example, Snow et al. (1980) stressed that among 60\% to $90 \%$ of adherents to religious groups were linked with activists before joining collective action. Similarly, Diani and Lodi (1988) showed that $78 \%$ of activists had prior connections with ecologists before participating in the environmental movement in Milan (see also della Porta 1988, Kriesi 1993, McAdam 1988, Passy 1998). Those studies highlight the fact that personal bonds serve to connect prospective activists with an opportunity for protest.

Relational embeddedness and personal bonds not only facilitate participation in protest action but they also discourage leaving it. For example, McPherson et al. (1992) stress that

\footnotetext{
${ }^{4}$ In the paper we focus essentially on social interactions in people's mind. It is nonetheless obvious that there is a dialogical process going on from individuals' minds to macro structures, and vice-et-versa (Berger and Luckman 1966, Giddens 1984, Steinberg 1993). Cognition and worldviews are thus not just in individuals' heads as Poletta (2006) points out.
} 
a high proportion of ties to members of other organizational members sustains participation. Sandall (1999) shows that close links with activists discourage demobilization. Passy and Giugni (2000) highlight the fact that involvement in a dense relational context ensures that activists remain in constant contact with the protest movement and the contentious issue on a day-to-day basis. This could trigger an interpretative process that shapes activists' cognitive toolkit, and sustains their contentious commitment.

It is thus important to join networks in order to participate in contentious politics. However, to avoid critics that see the networks thesis as tautological, given the spread of ties in which individuals are embedded (Piven and Cloward 1992), scholars started to specify which networks affect what. Ties specification has certainly deepened our knowledge concerning the relation between networks and participation, but has also revealed contradictory findings. By distinguishing organizational from private ties, some studies underscored that organizational ties are crucial for challenging movements, while private networks are more effective for more consensual ones (Diani and Lodi 1988). Some scholars underlined that private links are essential for risky forms of protest (della Porta 1995, McAdam 1986) while others stressed their role in protest entailing no risk (Passy 1998). Examining the strength of bonds, some studies claimed that weak ties between actors contribute more to diffusing protest through activists (Hedström et al. 2000, Sandell 2001) than strong ties (della Porta 1995, McAdam 1986). Studies analyzing centrality in networks by specifying individuals' location in relational settings also reveal contradictory findings. Some scholars pointed out that individuals who were more central in networks were more prone to participate in contentious action (Fernandez and McAdam 1989, Sandell and Stern 1999), while others reported quite the reverse (Nepstad and Smith 1999). Finally, many studies stressed that multiple ties are a key element for participating in protest (Diani 1995; Fernandez and McAdam 1988; Gould 1995; Mische 2003), while McAdam and Paulsen (1993) questioned what dimension of social ties is the most important for participating in protest. They concluded that neither organizational links nor strong ties are good predictors, but a strong commitment to a participatory identity, reinforced by ties, predicts activism. In other terms, it is strong identification with a specific milieu that accounts for participation in protest.

McAdam and Paulsen's study incited scholars to specify the processes at stake. While admitting that networks are important McAdam stated, 'however the meaning of these findings and, more importantly, the actual processes that account for them remain opaque' (2003: 296). Attempting to define the social mechanisms that link networks to protest participation. Kitts (2000) emphasized three distinct mechanisms: an information process whereby networks create opportunities to participate in protest; an identity mechanism in which social interactions create and reproduce identity; and a exchange process where networks favor the circulation of information among actors. McAdam (2003) also specified processes at stake by emphasizing that networks are involved in recruitment, identity linkages, and positive and negative influences susceptible of converting prospective activists into participants. Finally, Passy $(1998,2001,2003)$ stressed that social interactions intervene via three distinct mechanisms: a socializing and identity-building process, a structural-connection process that bridges prospective activists to protest opportunities, and, finally, a decision-shaping process in which conversational interactions influence 
meaning systems of prospective activists, thereby encouraging them to participate in protest. In actual fact, social processes as emphasized by Kitts, McAdam, and Passy share important similarities. From their accounts, we can distinguish three main processes at stake: an identity-building process, a connecting process, and finally an interactively influential process whereby, through exchanges and conversational activities, prospective activists develop or strengthen their decision to participate (or not) in protest action.

Scholars' efforts in specifying which networks affect what, and what social mechanisms are at stake, substantially enlarged our knowledge about the link between networks and protest commitment. Nevertheless, we face two main shortcomings. The first problem concerns empirical inconsistencies. Sometimes networks exist but do not favor participation, as in the anti-abortion movement in California (Luker 1984) or in the protest against a highway construction in Brisbane (Mullins 1987). Conversely, as in the study by Snow et al. (1980) on Hare Krishna, or Jasper and Poulsen's work on animals' rights protest stressed, participation occurs without networks. Second, findings on the specific characteristics of ties also face major inconsistencies, as we underlined above. We thus face discordant conclusions as Baldassarri (2009) pointed out (see also Diani 2007).

Regarding discordant findings, two problems emerge. First, inconsistency in findings is partly due to the diversity of protest action under scrutiny. Protest comes in many forms. Participating in protest that challenges power-holders on mainstream issues, such as environmental protection, is certainly not comparable to involvement in the civil rights movement in the sixties, or joining the Nicaraguan rebellion. Indirectly, scholars assume that networks have similar influences on all types of contentious processes, which could hardly be the case. We need to better specify the types of protest so far understudied in order to make sense of the variations. In addition, accounts describing the links between networks and protest participation rely mainly on case studies. There is a need for comparative case studies in order to make sense of variations and explain why networks are important in some protests and not in others. Activists come in many forms, too. We need to take different types of activism into account, something that has not so far been done systematically (see Klandermans 1997, Passy 2003 for exceptions), but which would help us to better understand variations in the influence of networks on participants in protest politics. Controversial results found in the literature suggest that the influence of networks has been overestimated. By focusing on social interactions, scholars have actually underestimated other processes at work, such as media influences, sociopolitical events, etc. We need to systematically compare social interactions with other processes influencing participation in order to assess the effective influence of networks.

The second shortcoming we face relates to the theoretical understanding of networks. Whereas scholars have underlined the influence of social interactions on individuals' meanings and cognitions (see in particular McAdam 2003, Passy 2003), we have largely neglected the construction of meaning in social interaction processes. We omitted to link social interactions and cognitive accounts in the social movement literature. Individuals are symbol-making creatures who spin webs of meanings around themselves, and these meanings allow them to act. As Jasper (1997) underlines, people try to make sense of the world and this implies that they often protest because their systems of meanings are at stake. However, our system of meanings is not uniquely made up of identity. Individuals 
are engaged in complex negotiations of meaning across multiple cognitive dimensions in order to join protest (Gamson 1992; Monsch and Passy 2011). To participate in protest, the construction of identity frames is essential, but in addition other action frames are needed, such as an elaboration of moral indignation, a perception that actors' participation could bring about social changes, etc. As stated above, social interactions intervene in creating and modifying individuals' cognitive toolkit. It is within the flux of discussions and conversational interactions that individuals develop not only their identity, but also other cognitive dimensions that are essential to participate in protest politics. We need to specifically analyze the construction of meanings, and the influence of social interactions on individuals' cognitive toolkit. We need also to disentangle the effects of social networks. Social interactions develop and transform individuals' cognitive toolkit but they also connect prospective activists to opportunities of protest. Social movement analysts should examine both processes separately in order to improve our knowledge on processes linking networks and participation, and to assess whether social interactions are (or are not) crucial factors in both processes.

\section{Cognitive Construction, Connecting processes, and Variations}

Engaging in protest does not depend on a decision that has taken place at one single moment, but is rather a dynamic process occurring over a lengthy period of time (Klandermans 1997, McAdam 2003, Opp and Gern 1993, Passy 2001). We should take time-span into account and study sequential accounts of the onset of individuals' action. Following the way paved by Klandermans (1997), we can segment protest participation into three main sequences. Before committing themselves to a protest action, individuals need first to be sensitized to a specific protest issue. They need to develop a frame of moral indignation in their cognitive toolkit, and perceive contention as a valuable repertoire of action designed to influence politics. People should develop a system of meanings that enables them to 'sympathize' with a movement. Secondly, in order to join a protest movement, individuals need to be motivated to participate. Moral indignation and the acceptance of protest as a valuable repertoire of action do not generate sufficient motivation to participate in a contentious action. They should identify with the protest actor and develop an agency frame, which enables them to perceive their contribution and that of the collective protest actor as able to bring about social changes. Finally, with all these meaning constructs in mind they will (or will not) participate in protest.

Networks should exercise considerable influence in the first two sequences: in sensitizing and motivating individuals to participate, in other words in creating, enriching, and modifying individuals' cognitive toolkit. Regular conversations with actors close to the protest issue favor the strengthening of political concern toward the protest issue. Similarly, regular conversations with people familiar with the contentious repertoire enable them to consider the repertoire as a valuable means of political action. Conversational interactions provide actors with other action frames - identity and agency frames - that motivated them to join protest action. Lisa's story well illustrates those processes. Political disputes provided her with cognitive tools. Progressively (but not linearly), the flux of discussions led her to create indignation frames in her mind, to develop cognitive awareness of the importance of being politically active in the associative 
milieu, to perceive protest action as a valuable means of influencing, even reversing, unfair state decisions, and finally to recognize that acting collectively could bring about social changes. Lisa's cognitive map, i.e. its nodes of meaning (Carley and Palmquist 1992), enabled her to develop strategies of action that moved her closer to protest politics. Networks intervened substantially in this process. However, other processes are also at work enriching individuals' cognitive toolkit. As Lisa's story also reveals, personal experience and reading also contributed to enriching her cognitive map, specifically in developing a political concern toward migrants' rights.

Beside networks, we distinguish two other processes that also contribute towards enriching actors' cognitive maps: self-interactions and external processes. Individuals not only interact with others but also with themselves, as Blumer (1969) taught us. Throughout their own life experiences, people develop and transform their mind map. They also enrich it through their quest for knowledge of the world around them, through their personal reading and their search for information ${ }^{5}$. We label these processes self-interactions whereby, through their own activity, people enlarge and modify their cognitive toolkit. Individuals' mind maps are also created and transformed by an external world that does not necessarily imply social interactions. Sociopolitical events - or sudden imposed grievances - such as wars, nuclear accidents or the massive deportation of clandestine migrants participate in developing and modifying individuals' cognitive toolkits by provoking 'moral shocks' (Jasper 1997). Eric Hobsbawm, who recently passed away, well illustrates our argument when he declared: 'Whoever personally witnessed Hitler's rise to power cannot avoid being politically influenced by those events. The child that I was then is still part of me and always will be'6. Besides sociopolitical events, collective protest actors also enrich and modify individuals' cognitive maps through their public actions (campaigns, advertisements, etc.) what the literature calls framing strategies (Snow et al. 1986). Individuals' cognitive toolkits are thus also being enlarged and transformed by what we call external processes. Beside social interactions, self-interaction and external processes contribute to the creation and transformation of cognitive elements within individuals' cognitive maps.

Networks intervene in modifying individual's cognitive toolkit. They also intervene in connecting sensitized and motivated actors (prospective activists) to a concrete opportunity for protest. Networks enable activists to participate in a specific contention by providing the bridges linking them to a social movement organization, an action campaign, a street demonstration, etc. They connect activists from one social site to another. This process takes place just before participating in protest, since individuals need to have developed the cognitive resources required to mentally link their cultural toolkit to a protest issue before participating in contention. Lisa was connected through the student movement to a squatter's milieu, and from both protests to the Legal Help Services to Exiled People by means of networks. This connecting process implies structural ties. An interpretative process may also occur by reinforcing and transforming cognitive dispositions, a process labeled by McAdam (2003) 'positive and negative influences' or 'shaping-decision process' by Passy (2003). During this connecting process prospective activists could strengthen

\footnotetext{
${ }^{5}$ We follow the thesis of selective exposure to media and information, whereby, beside other processes, networks could contribute in information selection done by individuals (Sears and Freedman 1967).

${ }^{6}$ Le Temps, October 2nd 2012.
} 
their sense of moral indignation and other action frames. Here again, as the literature underscores, networks provide the necessary bridges linking prospective activists to a protest opportunity. There are also other processes at work. In particular, collective protest actors themselves are highly involved in this process via recruitment campaigns. Beside social interactions, external processes also facilitate prospective activists to join protest.

Networks intervene in protest participation through both processes: a cognitive construction process and a connecting one. However, the importance of both processes varies according to the type of protest action. Contentious actions are more costly than others. To engage in challenging protest issues is more costly than participating in protest movements on consensual (or mainstream) contentious issues. In a similar vein, joining collective protest actors who benefit from high public visibility is less demanding for prospective activists than integrating a protest group with low public visibility. We hypothesize that networks do not play a uniform role in all protest situations. Social interactions are an important facilitator for individuals' cognitive construction and in connecting prospective activists to protest when the cost of action is high, simply because it is more difficult for individuals to develop cognitive resources and a motivated disposition in relation to challenging protest issues. For those protest actions, dense conversational interactions are particularly valuable since they enlarge and modify individuals' cognitive toolkits. In contrast, for mainstream contentious issues social interactions should be less important, whereas other processes, either self-interactions or external processes, should be more appropriate in developing political concern and a motivated disposition to act. Similarly, in order to participate in protest action benefiting from low public visibility, networks are fairly useful in creating a contact with such protest, whereas in connecting prospective activists to a high public visibility protest recourse to external processes, in particular, the collective protest actor itself is more effective in recruiting new-comers.

The cost of action is not only related to types of protest action but also to the intensity of activists' commitment. Becoming a highly active member is much more costly than becoming a sympathizer who merely financially supports a protest activity. Dense and multiple conversational interactions constitute a vital process in the development of resilient cognitive elements that can lead individuals to strongly commit to a specific protest: this includes the development of a deep sense of injustice, agency, identity, etc. Similarly, faceto-face interactions are probably more likely to drive prospective activists to a higher level of commitment than external processes of recruitment. In contrast, networks should play a lesser role for someone to become a sympathizer. Individuals' cognitive toolkits could be less furnished and a mere connection with the collective protest actor could be sufficient to trigger financial support to contention. 


\section{Method and Data}

We used a comparative research design to test our hypotheses. We compared three distinct types of protest action within Switzerland. These protest actions varied in terms of costs of action. We compared a highly challenging contentious issue led by a collective actor who has low visibility in the Swiss public space (Solidarity across borders) with a mainstream contentious issue benefiting from low public visibility (the Society for Threatened Peoples) and with, finally, a mainstream protest issue associated with a social movement organization that has the advantage of widespread public visibility (Greenpeace). Individuals who have joined Solidarity across borders, the Society for Threatened Peoples, and Greenpeace were facing widely dissimilar conditions in terms of the costs of commitment to those contentions. It was most demanding for individuals who participated in Solidarity across borders (SAB). People who commit themselves to defending migrants' rights are participating in one of the most challenging protests in Switzerland at the present time (Giugni and Passy 2004; Koopmans et al. 2005). They face a Federal state that has produced restrictive laws on migration and asylum, and a population who are not in favor of the enlargement of migrants' rights, but, on the contrary, widely support xenophobic referenda from the Populist Party. In addition, as for all protest actors in this contentious field, SAB faces difficulties in gaining access to public spaces in order to publicize their claims: it benefits from low public visibility. People participating in the Society for Threatened Peoples (STP) face easier conditions. This protest actor mobilizes within the human rights protest sector but on a fairly unknown issue: the defense of collective rights. STP brings social and political support to persecuted minorities in Europe and in other parts of the world. In the Swiss public sphere, both this issue, and the associated protest organization have low public visibility. For activists, it was rather costly to join such a 'confidential' protest. Finally, Greenpeace activists face the easiest conditions. Greenpeace mobilizes on one of the most consensual protest issues in Switzerland; even on energy policies the Swiss authorities support alternative energies (solar, wind energy, etc.) and have rejected the idea of future dependence on nuclear plants. As the opinion surveys emphasized, the Swiss population is also in favor of environmental protection. Moreover, Greenpeace, together with WWF are one of the most visible protest organizations in the Swiss public sphere. Activists who have joined this well-known organization, that enjoys high public visibility, mobilize on a mainstream issue involving few harsh political conflicts either with the public or power-holders.

To analyze the link between networks and protest participation we used survey data 7 . We distributed a standardized questionnaire with comparative indicators to members of the three organizations. In order to analyze active members who are always present in small numbers we stratified the sample to overestimate this category of activists. We stratified the samples for SAB and Greenpeace but not for STP, as this highly professional organization only mobilizes sympathizers ${ }^{8}$. Survey data based on representative samples

\footnotetext{
7 The data were collected between 2009 and 2010 for a larger project Why Stand Up for Others? A Comparative Study of Political Altruism and Contentious Participation that aims to understand protest commitment on behalf of others. The Swiss National Science Foundation financed this research project (100017-122246).

${ }^{8}$ We stratified the sample on the level of protest activism by dividing activists and sympathizers into two blocs representing $50 \%$ of the sampling for each stratum. We also stratified the sample on a regional
} 
were adapted to ascertain the influence of networks on contentious participation, and to gauge the importance of social interactions in comparison with other processes. This enabled us to identify a specific recurrent empirical relationship and to generalize our findings, which is something that Lisa's story and qualitative data are unable to do.

To assess the effect of networks on two processes - constructing individuals' cognitive maps, and in connecting prospective activists to a protest opportunity (bridging) - we used several indicators and proxies. We employed three types of indicator to ascertain the effect of social interactions on activists' cognitive maps. First, we examined prior embeddedness in organizational and private networks, as these were indicators of relational settings where activists could talk, interact and have political discussions that could develop, enrich and transform their cognitive toolkit. For organizational embeddedness we asked activists to tick an exhaustive list of organization 'families' (feminist, human rights, religious, etc.) of which they already committed to before joining $\mathrm{SAB}$, STP, or Greenpeace ${ }^{9}$. Regarding embeddedness in private networks, we asked interviewees if they were evolving in a private relational setting that was sensitive to the protest issue of their future commitment before joining SAB, STP, and Greenpeace ${ }^{10}$. For each type of ties (friends, acquaintances and family members) we asked respondents to indicate the importance of their political concern toward the protest issue. For example, if their close friends were all, most of them, half of them, only a small number, or none of them concerned by the issue. Second, as highlighted in the theoretical section, individuals need to be sensitized to a specific issue and to perceive contention as part of a valuable action repertoire that could influence politics before resorting to protest. Here, we used a proxy by means of a question asking activists what sensitized them to the protest issues (respectively migrant's rights, autochthonous population' rights, and environmental protection). This indicator aimed to establish what contributed to developing an injustice frame in their mind. They were invited to tick relevant items from a long list of channels and processes (close friends, readings, media, political events, etc.) that enabled them to construct a feeling of moral indignation ${ }^{11}$. Third, with a similar question and response format we measured what motivated them to participate. To be motivated to participate in a specific protest implies that individuals have developed not only an injustice frame but also other action frames such as identity and agency frames. We measured the influence of networks on cognitive maps with a proxy asking activists what encouraged them to participate in the defense of migrant's rights, autochthonous population rights, or to become involved in environmental protection ${ }^{12}$.

dimension in order to overestimate the French speaking part of Switzerland. Here again, we split Switzerland in two regions - French and German - where each represents $50 \%$ of the whole sample.

9 The question was the following: 'Here is a list of associations or groups. Could you tell us if you were a member of or already committed to these associations before joining $S A B$ (STP or Greenpeace)'?

10 'Before joining SAB (STP or Greenpeace) were close friends, acquaintances and family members sensitive to or aware of the problem of migrant's rights (autochthonous population' rights or environmental protection)?'

11 'What sensitized you or made you aware of the problems of migrants' rights (autochthonous population' rights or environmental protection)?' (Many responses are possible please cross all items in the list below that sensitized you to the protest issue).

12 'What encouraged you to participate in the defense of migrants' rights (autochthonous population' rights or environmental protection)?' (Many responses are possible. Please cross all items in the list below that induced you to participate). 
To ascertain the role of social networks on connecting prospective activists to protest opportunities we used two indicators. The first indicator was based on a question asking activists by what means they entered into contact with SAB, STP, or Greenpeace. They could select three from a list of eight possibilities (including networks but also other options) ${ }^{13}$. The second indicator focused on the influence of existing members that activists had known before joining the organization, and who had encouraged them to become members. In this case we asked them to specify the quality of the tie (friends, acquaintances, or family members), and the degree of commitment of the member(s) (active members or sympathizers) $)^{14}$.

Survey data face several shortcomings. First, social mechanisms and the meanings of network influences are difficult to grasp when working with such data and indicators. Similarly, it is difficult, when working with quantitative indicators, to evaluate the effect on individuals' cognitive toolkits of conversational interactions that continuously generate, strengthen, and modify these same cognitive processes. In order to analyze more accurately the social mechanisms at work, as well as the effects of social interactions on individuals' cognitive toolkits we need qualitative data (McAdam 2003, Mische 2003, Siegel 2009). Qualitative corpuses have been collected through life history narratives and in-depth interviews with activists. They are not included here due to space constraints but they did help us to make sense of our quantitative material and to interpret correlations found.

Secondly, a one-shot survey raises the problem of not being able to trace a participation process that can extend over a rather lengthy period of time and includes several stages: to be sensitized; becoming motivated to act; and, finally, joining a protest action. As it is impossible to follow a large number of individuals throughout this lengthy process, we used retrospective questions in order to reconstruct a temporal perspective, taking into account the three stages defined theoretically. However, retrospective data also raises problems. They may be biased due to memory distortion and the tendency of actors' working on past recall to offer a coherent view of their life and themselves. Should we trust our data and findings? Yes, to a certain extent. First, many social psychologists have recently contested Festinger's (962) account (Fiske and Taylor 2008). We tolerate many more inconsistencies than suggested by previous research, and we are able to verbalize them, as well as to present to others a life made up of contradictions. Second, in the present analysis we relied mainly on factual data that are less susceptible to reconstruction, memory distortion, and forgetting. Finally, reliability tests made on retrospective data did not endorse problems that we usually advanced (Coen van Rij 1994). Whereas we are aware of these limitations, and therefore discuss our results in the light of these shortcomings, they do not prevent us from tentatively assessing the effects of social networks on protest participation.

\footnotetext{
13 'Could you tell us how you entered into contact with SAB (STP or Greenpeace)? Was it by means of... (Maximum: 3 responses).

14 Before joining $S A B$ (STP or Greenpeace) did you personally know an activist (or many) that incited you to become a member of the SAB (STP or Greenpeace)?' If yes: 'What was your connection with this person (a friend, an acquaintance, a colleague, a family member)? (If you knew many activists, please provide information for the two most influential persons. 'What was his/ her level of commitment in the organization'.
} 


\section{Social Interactions and the Construction of Meanings}

Are activists embedded in dense relational settings before joining protest that could, through conversational interactions, enrich or modify their cognitive toolkit? Does prior affiliation with networks vary according to the type of protest action? Is it more important for costly forms of activism than less constraining types of protest action? And, finally, does prior embedding in relational settings affect the commitment intensity of future activists? Let us empirically examine these questions.

Examining activists' prior embedding in organizational networks, we clearly see from Table 1 that before joining SAB, STP, and Greenpeace, activists were involved in a dense network of organizational settings in which they conducted multiple conversational interactions. However, not every relational embedding was able to enrich or transform cognitive tools in connection with their future protest action, whether it is promoting the rights for migrants, autochthonous peoples' rights, or environmental protection. Interactions within relational settings sharing worldviews and identity (or master frames ${ }^{15}$ ), as well as boundary interpenetrations with the future protest commitment, were more prone to develop cognitive resources that activists would need in order to join their future protest group, than social interactions occurring without those implied meanings and identity links. SAB, STP, and Greenpeace activists were mainly embedded in organizational networks of the postindustrial protest sector before joining these three contentions. Through discussions and conversational interactions, such specific embedding was most able to develop a political concern and motivational dispositions to join these three protests ${ }^{16}$. Activists were thus already involved in dense relational settings where they interacted and discussed protest issues close to their future commitment.

\section{Table 1 about bere}

However, important variations should be noted. Activists involved today in the defense of migrants' rights (SAB), a challenging protest issue mobilized by protest actors benefiting from low public visibility, were widely embedded in organizational settings: $72 \%$ were involved in postindustrial networks. In addition, they were embedded in a denser organizational setting, since they were members of various groups within the postindustrial sector (mean 2.3, see the second block of Table 1). Conversational interactions played a more prominent role for them than for activists mobilizing for STP. Those activists were less embedded in postindustrial networks $(57 \%)$ and had fewer ties with this milieu (mean 1.3). In contrast, Greenpeace activists who joined a mainstream protest issue endorsed by a highly visible contentious actor in the Swiss public space were much less embedded in organizational settings. Only 33\% of those activists were involved in postindustrial networks before joining Greenpeace. And they were weakly tied to this milieu, as some of them were not even members of one group (mean 0.6). Prior conversational interactions of future activists were rather limited for Greenpeace compared to the Society for Threatened Peoples, and above all Solidarity across borders.

\footnotetext{
15 See Snow et al. (1992).

16 Postindustrial movements are also labeled 'new social movements' or 'new left movements'.
} 
Whereas the cost of entry into distinct types of protest matters, it is also true for intensity of activism. People who were involved in postindustrial organizations and were embedded in a dense relational setting were driven toward the highest degree of commitment in their future protest action. This was specifically true for activists joining costly contentions, such as the defense of migrants' rights. Activists who had dense conversational interactions were more prone to join SAB as active members (.32***). For less demanding protest groups, such as Greenpeace, those interactions have also driven activists to a higher level of commitment but to a comparatively lesser extent than for costly forms of protest $\left(.14^{*}\right)^{17}$.

Before joining a protest actor, all types of activists were also embedded in dense conversational interactions in their private relational settings. As Table 2 emphasizes, almost all protestors had private networks sensitive to the political issues of their future contentious commitment. And those interactions took place with strong ties (close friends or family members). About half of activists interacted with strong ties partly concerned by their future protest issue, while another half interchanged with close ties that were highly preoccupied by this issue. Discursive contacts took place in trust networks and on a regular basis: this type of interpersonal exchange was most susceptible to influence and modify activists' cognitive maps. Contrary to anchorage in organizational settings, few variations were discernible here. All types of activists were highly involved in a dense private relational setting concerned by the political issue of their future protest commitment. However, protestors who will join a migrants' rights protest mainly interacted with strong ties which were highly concerned by migrants' problems, while for activists joining mainstream protest issues (benefiting or not from pubic visibility) such types of interaction are slightly weaker. Apart from this small difference, conversational interactions in private networks were important for all type of protest, as well as all types of activism. Activists and sympathizers shared a similar relational context before joining their future protest.

\section{Table 2 about bere}

Before joining their respective protest, activists were thus highly embedded in networks where discussions and political debates were important elements capable of providing them with cognitive resources to create, strengthen or modify a frame of moral indignation, as well as motivational dispositions related to their future commitment. As summarized in Table 3, few actors were solely engaged in conversational interactions within organizational networks, but were instead mainly interacting within private networks, or in both private and organizational relational settings. This result highlights, and also confirms, many research findings, namely that interactions in a private sphere sensitive to the protest issue are of great importance prior to joining a contentious actor. Such interactions, and specifically those with strong ties, are able to influence and modify individuals' cognitive capacities in ways that enable them to develop action strategies.

But variations do occur. Before participating in challenging contentious action, such as the defense of migrants' rights', people were involved in dense relational settings where

\footnotetext{
17 We could not run similar analyses for STP as they mobilize only sympathizers (see Method and Data).
} 
conversational interactions in both organizational and private networks seemed to be necessary. Almost all activists (87\%) benefited from such a conversational environment before engaging in SAB. In contrast, for activists who protest on mainstream contentious issues with low public visibility, their conversational environment was fairly different. Embedding in both organizational and private networks was less important for them than for protestors engaged in challenging contentious issues (55\%). And this conversational environment was even less important for activists who will join protest action mobilizing on mainstream issue benefiting from high visibility in the public sphere (38\%). To join this type of protest, discussion in private networks seem to be sufficient to provide such activists with the cognitive tools that enabled them to participate in this less demanding protest action.

\section{Table 3 about bere}

Although the type and strength of future activists' insertion in relational settings varied, the findings stressed that individuals were nonetheless all engaged in dense conversational interactions before joining SAB, STP and Greenpeace. But are those interactions a key factor for developing or reinforcing political concern regarding migrants' rights, autochthonous peoples' rights and environmental problems? Or are other processes at work to sensitize them to their respective protest issue? Table 4 clearly indicates that other processes were at work to sensitize individuals to their future respective contentious issue. About $80 \%$ were sensitized by self-interactions, in particular through their search for information and personal reading, while about $75 \%$ constructed a moral indignation frame through external processes: either through the contentious actor itself (SAB, STP, or Greenpeace) thanks to their framing strategies, or by means of sociopolitical events related to migration, autochthonous peoples or environmental protection. Multiple processes were thus at work to sensitize future activists to their respective contentious issue and contribute to the development or strengthening of their frame of moral indignation related to this protest issue. As the second block of Table 4 highlights, in order to develop and modify individuals' cognitive toolkit many processes were involved. For most of the activists either two processes - in particular a combination of self-interactions and external processes - or all three processes - social interactions, self-interactions, and external processes - were necessary to develop a feeling of concern about the protest issue.

\section{Table 4 about bere}

Conversational interactions were thus merely one process among others. Almost no activists were uniquely sensitized through social networks; instead, a plurality of processes was required to enrich and modify individual's cognitive toolkit. However during these processes social interactions did play a role. About half of future protestors became aware of migrant's rights, autochthonous peoples' rights or environmental problems by means of conversations or political discussions in their social networks. But it is clear that social interactions were not the main sensitizing processes, nor the most important one. However, as we see in Table 4 social interactions are slightly more important in the case of challenging contentions (58\%) than for other types of protest $(38 \%$ and $46 \%)$. 
Generally speaking, conversational interactions comprise one process among others in sensitizing individuals; this is even more noticeable when motivating actors to protest against unfair migration and asylum policies, injustices undergone by autochthonous populations or in struggles to establish environmental protection. Once actors have developed an injustice frame, and mentally accept that protest can be a valuable element in the action repertoire of political contention, they still have to develop identity and agency frames, and other cognitive tools in order to join a contentious field. In this cognitive process, as Table 4 shows (right-hand columns), self-interactions, either through private reading or personal experience, together with external processes, in particular through the framing strategies of protest organizations, are much more important than social interactions. Among the variety of routes that help individuals to develop, reinforce or modify their motivational dispositions, conversational interactions were not, and by far, the main process that motivated individuals to participate in protest action. However, there are variations to this generalization. To motivate activists to join challenging contention, such as the defense of migrants' rights, social interactions are much more important $(45 \%)$ than to mobilize activists to participate in mainstream issues, whether or not such issues have high or low visibility in the public space $(15 \%$ and $23 \%)$. In the latter case, selfinteraction and external processes were key factors in motivating activists, whereas conversational interactions marginally contribute to the construction of motivational dispositions that later led to participation in contentious politics.

Conversational interactions in social networks were not only vital in mobilizing for demanding protest actions, they also played an essential role in driving individuals to a higher intensity of commitment. For activists of challenging protests $(\mathrm{SAB}, .08 * / .12 *)$, as well as for mainstream movements (Greenpeace, .16***/.15***), these interactions encouraged individuals to become active members rather than sympathizers.

Thus, although activists were highly embedded in relational settings, networks were not the main process for sensitizing them to the issues, and even less for motivating activists to participate in protest politics. To provide future activists with cognitive resources, other processes play their part. We should thus not reify the role of social interactions in the process of constructing meanings. However, conversational interactions were important to sensitize activists to a protest issue and even more so when motivating them to engage in costly protest action, such as the migrant's rights issue; networks diminished in importance for less demanding protest actions, such as autochthonous peoples' rights or environmental protection. Finally, the flux of talks in networks was a route that sensitized and motivated people who would eventually become active members in their future protest action. Conversational interactions were thus more important for costly and demanding forms of activism.

\section{Connecting Actors to a Protest Opportunity}

Activists develop political concern for a protest issue, as well as achieving a level of motivation that enables them to act; then, finally, they will participate (or not) in contentious action. In this last sequence, are networks important in providing a bridge linking prospective activists to a concrete protest opportunity? Here again, are other processes at work, and, 
as highlighted by some scholars, are social interactions not a key facilitating factor? The response to this question largely depends on the type of protest action. As Table 5 underscores, to join a challenging protest, such as SAB, networks were important in connecting prospective activists to the protest opportunity. More than a half of activists joined SAB by means of networks. However, for people joining mainstream protest issues, with high or low public visibility, as was the case for participants in the STP or in Greenpeace, social interactions were not important connectors. Only one-fifth of those activists joined both protest groups by means of networks. STP and Greenpeace activists were mainly drawn toward those contentious organizations through contact with the protest activists. In other terms, it was thanks to the organizations' efforts that prospective activists have been induced to join STP and Greenpeace. The main difference between STP and Greenpeace activists relates to the importance of the media. Beside its own recruitment campaigns to attract new members, information and reports in the media concerning its on-going campaigns and claim-making provide important connectors between prospective activists and the ecologist organization. In contrast, for STP, benefiting from low public visibility, the media do not act as an important connector bridging potential activists into the organization.

Social interactions are more important for costly protest actions. Networks enable prospective activists to join more demanding contentions. While for easiest protest actions, as is the case for STP or Greenpeace, social interactions were much less necessary, even not important connectors at all. In a similar vein, activists' networks were far more important for active members, than for less demanding forms of participation, such as financially supporting a protest group without being involved in a active process of mobilization. Although social interactions resulted in a stronger intensity of commitment for activists joining less demanding types of protest, for example mobilizing in Greenpeace (.17***), this was even more marked for challenging forms of protest. Prospective activists who had been bridged to $\mathrm{SAB}$ by means of networks were more prone to belong to the narrow circle of active members $(.24 * * *)$.

\section{Table 5 about bere}

The literature has extensively emphasized that prior personal bonds with leaders or influential members are a key factor favoring participation in contention. Is that really the case? The answer is no, but here again it varies according to types of protest. As Table 6 highlights, $41 \%$ of activists who joined the costly protest defending migrant's rights were linked with a known activist from this organization, and this bond induced them to participate in SAB. In contrast, for mainstream protest issues, and even more so for the less visible organization mobilizing on a mainstream issue (STP), few activists joined these protest opportunities through contact with influential members. For activists who have been induced to join protest through influential members, those members were mainly strong ties and active participants of those organizations (except for Greenpeace where sympathizers could also bridge prospective activists into the organization).

Table 6 about bere 
Here again, for costly types of protest, networks were more important connectors. Moreover, those connectors are more important for costly forms of activism. Activists benefiting from personal bonds with the protest opportunity became, to a large extent, active members. In the case of challenging protest actors, the mere fact of having such bonds constituted a strong inducement to join the circle of active members (.31***). And if those bonds were close friends or family members (strong ties), that was an added incitation for them to be more active $\left(.15^{*}\right)$. For less demanding forms of protest, e.g. Greenpeace, the mere fact of enjoying such ties propelled prospective activists to higher levels of commitment $\left(.10^{*}\right)$, the more so if those bonds were themselves active members $\left(.31^{* * *}\right)$.

\section{Conclusion}

Let us turn to the questions raised in the introduction. Do networks really matter in contentious politics? From our findings the response is 'Yes, they do' for certain types of protest. However, their importance should not be overestimated, even for protests where networks do play a significant role. Other processes are at work in developing, reinforcing, and modifying individuals' cognitive tools as well as connecting prospective activists to mobilizing opportunities, and those processes are usually more important than networks. Social interactions are not the main process at work, rather they constitute one process among others. Self-interactions (individuals own experiences, personal reading, and the search for information), and external processes (above all framing strategies led by collective protest actors themselves) are also, and for certain types of protest, key processes leading individuals toward contentious politics. Network impact must thus not be reified.

The first question could in fact be answered in the light of our second main question: Are social networks important for all types of protest? The response is clearly no. The effect of social networks varies greatly according to the costs involved in contentious action. For costly protest actions, which are more demanding for individuals who join such contentions, networks play a much more important role than for less costly protests. We distinguished two dimensions that influence the costs of action: first, the type of contentious issue, in which we contrasted issues that are challenging in the public arena (migrant's rights), with mainstream protest issues (autochthonous peoples' rights and environmental protection), and, second, the level of visibility in the public sphere, by comparing Greenpeace with SAB and STP. For those dimensions, the nature of the protest issue is determinant, while public visibility of the protest actors counts for much less, if at all. Conversational interactions play a major role in developing, strengthening, or modifying individuals' cognitive toolkits that help in sensitizing, and motivating individuals to participate in challenging protest. In contrast, inner interactions and external processes contribute much more to the development of individuals' cognitive map in mainstream contentious issues. Similarly, in order to join challenging protest actors, networks are much more important connectors than they are for joining contentions concerning consensual issues. The intensity of political conflicts linked to the issues mobilized by the collective contenders increases the importance of networks for both construction of meanings and bridging processes. 
Social interactions also vary according to the intensity of activists' commitment. Once again, for the most costly forms of activism networks play a more important role than for less costly forms of activism. Conversational interactions taking place before participation are more apt to develop and enrich individuals' cognitive map that in turn creates a high intensity of commitment among those actors. Similarly, being bridged to the contentious opportunity by networks leads activists to a higher degree of participation. Networks are thus a crucial factor in bringing people to bigher level of commitment: that is to engage in a more costly form of activism.

Finally, we raised a last question: What are social networks and in which they are important? Contrary to scholars who emphasize that social interactions are important for identitybuilding, to develop 'participatory identity' enabling individuals to join contentions, we argue that social interactions - through talks, discussions and discourse - influence not only an individual's identity frame of action but also other cognitive elements that are essential when participating in protest politics; for example those emphasized by Gamson (1992): injustice and agency frames. Conversational interactions nourish, enlarge, strengthen or modify individuals' toolkit of cognitive components that enable actors to act. Our findings stress that conversational interactions are important in sensitizing to a protest issue: to develop moral indignation regarding a specific political problem, and mentally construct that the contentious repertoire is a valuable means for acting politically. Although this process is slightly more important for people who will join challenging protest issue, it is essential for all three types of protest. In contrast, when it is a question of motivating actors to participate in protest, those interactions are less efficient, in particular for less challenging protest issues. Other processes enrich individuals' cognitive toolkit with motivational dispositions. In particular, collective protest actors, by means of their framing strategies, are much more apt to develop identity and agency frames that would motivate individuals to participate in protest. Finally, besides the construction of meanings, networks also intervene at the end of individuals mobilizing process by bridging them to a concrete contentious opportunity. In this process networks play a peripheral role. Once again their role is much more important in connecting individuals to challenging protest, but even so they are not as important as the literature usually states. Our findings show that networks are important in sensitizing prospective activists to a protest issue, but are less important for motivating, and leading them to act, once we compare networks with other processes at work.

In this paper we contributed first to assigning networks to their rightful place, and not reifying their influence on the participation processes; second, we identified and explained variations in network effects on protest participation; and finally, we specified network impact on contentious participation, that is, we disentangled different processes at work theoretically, but also by making an empirical effort to analyze the interpretive and connecting processes of networks on participation. What are the directions for future research? We would like to emphasize two main directions. First, and in relation to our last point - in which networks are important, we need more research on the influence of social interactions on individuals' cognitive toolkit. As mentioned in the methodological section, survey data are not the best-adapted data for examining the creation, strengthening and transformation of individuals' actions frames. There is still a need for much more empirical effort to examine how those components concretely intervene in 
the lengthy process of individual commitment to contentious politics. For that, qualitative materials are needed. They will enable a more accurate analysis of the effects of conversational interactions on cognitions, meanings and worldviews. Such studies would enable social movement scholars to distance themselves from the 'structural bias' in which social movement literature has often fallen (Goodwin and Jasper 2003). They would also provide empirical grounds for the interpretative understanding of networks developed by White (1992). Finally, such work would better link network accounts in the social movement literature with the cognitive perspective developed by Gamson, Klandermans, McAdam, and other scholars. While many scholars claim progress in locating such a linkage, until now this link is allusive rather than tangible.

A second direction for future research is to develop comparisons more systematically in order to understand and explain variations at work. Protest is of diverse forms and networks do not have a uniform, or universal, influence on participants in contentious politics. As we have stressed, their influence varies strongly according to the costs of action. By comparing other forms of activism, more key factors would certainly emerge that would help to explain variations in the links between networks and participation. Until now, work on social networks relied merely on single case studies that, as a consequence tend to provide discordant findings. To integrate variations of contentions would strengthen our knowledge and help us to make sense of those discordant findings by illuminating why in certain protest contexts networks are important, in others not, or much less. 


\section{References}

Baldassarri, D. (2009) Collective Action, in: P. Hedström \& P. Bearman (Eds) Oxford Handbook of Analytic Sociology, pp. 391-418 (Oxford: Oxford University Press).

Berger, P. L. \& Luckmann, T. (1966) The Social Construction of Reality: A Treatise in the Sociology of Knowledge (Garden City, NY: Anchor Books).

Blumer, H. (1969) Symbolic Interactionism (Berkeley, CA: University of California Press).

Carley, K. \& Palmquist, M. (1992) Extracting, Representing, and Analyzing Mental Models, Social Forces, 70, pp. 601-36.

Coen van Rij, J. (1994) To Join or Not to Join: An Event-history Analysis of Trade-Union Membership in the Netherlands, PhD Thesis. University of Amsterdam.

della Porta, D. (1988) Recruitment Processes in Clandestine Political Organizations: Italian Left-Wing Terrorism, in: B. Klandermans, H. Kriesi, \& S. Tarrow (Eds) From Structure to Action, pp. 155-72 (Greenwich, CT: JAI Press).

Diani, M. (1995) Green Networks: A Structural Analysis of the Italian Environmental Movement (Edinburgh: Edinburgh University Press).

Diani, M. (2007) Networks and Participation, in: D. Snow, S. Soule \& H. Kriesi (Eds) The Blackwell Companion to Social Movements, pp. 339-59 (Oxford: Blackwell).

Diani, M. (forthcoming) Organizational Fields and Social Movement Dynamics, in: B. Klandermans, C. Roggeband \& J. Van Stekelenburg (Eds) Advancements in Social Movements Research (Minneapolis: University of Minnesota Press).

Diani, M. \& Lodi, G. (1988) Three in One: Currents in the Milan Ecology Movement, in: B. Klandermans, H. Kriesi, \& S. Tarrow (Eds) From Structure to Action, pp. 155-72 (Greenwich, CT: JAI Press).

Emirbayer, M. (1997) Manifesto for Relational Sociology, American Journal of Sociology, 103, pp. 281-317.

Emirbayer, M. \& Goodwin, J. (1994) Network Analysis, Culture, and the Problem of Agency, American Journal of Sociology, 99, pp. 1411-54.

Emirbayer, M. \& Mische, A. (1998) What is Agency, American Journal of Sociology, 103, pp. 962-1023.

Fernandez, R. M. \& McAdam, D. (1988) Social Networks and Social Movements: Multiorganizational Fields and Recruitment to Mississippi Freedom Summer, Sociological Forum, 3, pp. 357-38.

Festinger, L. (1962) A Theory of Cognitive Dissonance (Stanford, CA: Stanford University Press).

Fiske, S. T. \& Taylor, S.E. (2008) Social Cognition. (Columbus: McGraw-Hill).

Gamson, W. (1992) Talking Politics (Cambridge: Cambridge University Press).

Giddens, A. (1984) The Constitution of Society: Outline of the Theory of Structuration (Los Angeles: University of California Press).

Giugni, M. \& Passy, F. (2004) Migrant Mobilization Between Political Institutions and Citizenship Regimes. A Comparison of France and Switzerland, European Journal of Political Research, 43, pp. 51-82.

Goodwin, J. \& Jasper, J.M. (2003) Caught in a Winding, Snarling Vine. The Structural Bias of Political Process Theory, in: J. Goodwin \& J.M. Jasper (Eds) Rethinking Social Movements (Boulder: Rowman and Littlefield). 
Gould, R. V. (1995) Insurgent Identities. Class, Community, and Protest in Paris from 1848 to the Commune. (Chicago: Chicago University Press).

Hedström, P., Sandell, R. \& Stern, C. (2000) Mesolevel Networks and the Diffusion of Social Movements. The Case of Swedish Social Democratic Party, American Journal of Sociology, 106, pp. 145-72.

Jasper, J. (1997) The Art of Moral Protest: Culture, Biography, and Creativity in Social Movements (Chicago: University of Chicago Press).

Jasper, J. \& Poulsen J. (1993) Fighting Back: Vulnerabilities, Blunders, and Countermobilization by the Target of Three Animals Campaigns, Sociological Forum, 8, pp. 639-57.

Kitts, J. (2000) Mobilizing in Black Boxes: Social Movements and SMO Participation. Mobilization, 5, pp. 241-57.

Klandermans, B. (1997) The Social Psychology of Protest (Oxford: Blackwell).

Koopmans, R., Statham, P., Giugni, M. \& Passy, F. (2005) Contested Citizenship. Immigration and Cultural Diversity in Europe (Minneapolis: University of Minnesota Press).

Kriesi, H. (1988) Local Mobilization for the People's Social Petition of the Dutch Peace Movement, in: B. Klandermans, H. Kriesi, \& S. Tarrow (Eds) From Structure to Action, pp. 155-72 (Greenwich, CT: JAI Press).

Kriesi, H. (1993) Political Mobilization and Social Change (Aldershot: Avebury).

Luker, K. (1984) Abortion and the Politics of Motherhood (Berkeley: University of California Press).

McAdam, D. (1986) Recruitment to High Risk Activism: The Case of Freedom Summer, American Journal of Sociology, 92, pp. 64-90.

McAdam, D. (1988) Freedom Summer (New York: Oxford University Press).

McAdam, D. (2003) Beyond Structural Analysis: Toward a More Dynamic Understanding of Social Movements, in: M. Diani \& D. McAdam (Eds) Social Movements and Networks. Relational Approaches to Collective Action, pp. 281-98 (Oxford: Oxford University Press).

McAdam, D. \& Paulsen, R. (1993) Specifying the Relationship between Social Ties and Activism, American Journal of Sociology, 99, pp. 640-67.

McPherson, M., Popielarz, P. \& Drobnic, S. (1992) Social Networks and Organizational Dynamics, American Sociological Review, 57, pp. 153-70.

Melucci, A. (1989) Nomads of the Present (Philadelphia: Temple University Press).

Meyer, D. S. \& Whittier, N. (1994) Social Movement Spillover, Social Problems, 41, pp. 277-98.

Mische, A. (2003) Cross-Talk in Movements: Reconcieving the Culture-Network Link, in: M. Diani \& D. McAdam (Eds) Social Movements and Networks. Relational Approaches to Collective Action, pp. 258- 80 (Oxford: Oxford University Press).

Mische, A. (2011) Relational Sociology, Culture, and Agency, in: J. Scott and P. Carrington (Eds.) Sage Handbook of Social Networks Analysis (London: Sage).

Mische, A. \& White H.C. (1998) Between Conversation and Situation. Public Switching Dynamics across Networks-Domain, Social Research, 65, pp. 695-724.

Monsch, G.-A. \& Passy, F. (2011) The Mind of Activists : A Cognitive Approach to Contentious Participation. University of Lausanne.

Mullins, P. (1987) Community and Urban Movements, Sociological Review, 35, pp. 347-69. 
Nepstad, S. E. \& Smith, C. (1999) Rethinking Recruitment to High Risk/Cost Activism: The Case of Nicaragua Exchange, Mobilization, 4, pp. 25-40.

Oberschall, A. (1973) Social Conflict and Social Movements (Englewood Cliffs: Prentice-Hall).

Oliver, P. E. (1984) 'If You Don't Do It, Nobody': Active and Token Contributors to Local Collective Action, American Sociological Review, 49, pp. 601-10.

Opp, K-D. \& Gern, C. (1993) Dissident Groups, Personal Networks, and Spontaneous Cooperation: The East German Revolution of 1989, American Sociological Review, 58, pp. 659-80.

Passy, F. (1998) L'action altruiste. Contraintes et opportunités de l'engagement individuel dans les mouvements sociaux (Paris: Droz).

Passy, F. (2001) Socialization, Connection, and the Structure/Agency Gap. A Specification of the Impact of Networks on Participation in Social Movements, Mobilization, 6, pp. 173-92.

Passy, F. (2003) Social Networks Matter. But How ? : M. Diani \& D. McAdam (Eds) Social Movements and Networks. Relational Approaches to Collective Action, pp. 21-48 (Oxford: Oxford University Press).

Passy, F. \& Giugni, M. (2000) Life-spheres, Networks, and Sustained Participation in Social Movements. A Phenomenological Approach to Political Commitment, Sociological Forum, 15, pp. 117-44.

Piven, F. F. \& Cloward, R. (1992) Normalization Collective Protest, in: A. Morris \& C. Mueller (Eds) Frontiers in Social Movement Theory, pp. 301-25 (New Haven: Yale University Press).

Polletta, F. (2006) It Was Like A Fever. Storytelling in Protest and Politics (Chicago: University of Chicago Press).

Sandall, R. (1999) Organizational Life aboard the Moving Bandwagons: A Network Analysis of Dropouts from a Swedish Temperance Organization, 1896-1937. Acta Sociologica, 42, pp. 3-15.

Sandell, R. (2001) Organizational Growth and Ecological Constraints: The Growth of Social Movements in Sweden, 1881 to 1940, American Sociological Review, 66, pp. 672-93.

Sandell, R. \& Stern, C. (1988) Group Size and the Logic of Collective Action: Network Analysis of a Swedish Temperance Movement 1896-1937, Rationality and Society, 10, pp. 327-45.

Sears, D. O. \& Freedman, J.L. (1967) Selective Exposure to Information: Critical Review. Public Opinion Quarterly, 33, 194-213.

Siegel, D. A. (2009) Social Networks and Collective Action, American Journal of Politic Science, 53, pp. $122-38$.

Snow, D. A. \& Benford, R. D. (1992) Master frames and cycles of protest, in: A. Morris \& McClurg Mueller, C. (Eds) Frontiers in Social Movement Theory, pp. 133-55. (New Haven, CT: Yale University Press).

Snow, D. A., Rochford, E.B., Worden, S.K., and Benford, R.D. (1986) Frame Alignment Processes, Micromobilization, and Movement Participation, American Sociological Review, 51, pp. 464-81.

Snow, D. A., Zurcher, L. A. \& Ekland-Olson, S. (1980) Social Networks and Social Movements: A Microstructural Approach to Differential Recruitment, American Sociological Review, 45, pp. 787-801.

Swidler, A. (1986) Culture in Action: Symbols and Strategies, American Sociological Review, 51, pp. 273-86.

Steinberg, Marc W. (1993) A Dialogue with Fine and Sandstrom from a Dialogic Perspective Turn, Sociological Theory, 11(3), pp. 314-320.

Tilly, C. (1978) From Mobilization to Revolution (Englewood Cliffs: Prentice-Hall).

Tilly, C. (1998) Contentious Conversations, Social Research, 65, pp. 491-510. 
White, H. C. (1992) Identity and Control (Princeton: Princeton University Press). 
Table 1: Activists' embeddedness in organizational networks before joining Solidarity across borders (SAB), the Society for Threatened Peoples (STP), and Greenpeace (GP)

\begin{tabular}{|c|c|c|c|c|c|c|}
\hline & \multicolumn{3}{|c|}{ Activists from } & \multicolumn{2}{|c|}{ Intensity of commitment } \\
\hline & & SAB & STP & GP & SAB & GP \\
\hline Social and pol. embeddedness & & $\%$ & $\%$ & $\%$ & Pearson's $r$ & Pearson's $r$ \\
\hline All type of networks & & 76 & 68 & 38 & $.26^{* * *}$ & ns \\
\hline Postindustrial & & 72 & 57 & 33 & $.32^{* * *}$ & ns \\
\hline Religious and charitable & & 45 & 35 & 14 & $.10^{* *}$ & ns \\
\hline Work & & 34 & 18 & 9 & ns & ns \\
\hline Political parties & & 26 & 11 & 3 & ns & ns \\
\hline \multirow[t]{2}{*}{ Other } & & 43 & 37 & 19 & $.10^{*}$ & ns \\
\hline & $\mathrm{n}$ & $(878)$ & (434) & $(761)$ & & \\
\hline Embeddedness density & & Mean & Mean & Mean & Pearson's $r$ & Pearson's $r$ \\
\hline \multirow{3}{*}{$\begin{array}{l}\text { Number of affiliations } \\
\text { within the postindustrial } \\
\text { sector }\end{array}$} & & 2.3 & 1.3 & 0.6 & $.32^{* * *}$ & $.14^{*}$ \\
\hline & & $(2.0)$ & (1.5) & (1.1) & & \\
\hline & $\mathrm{n}$ & $(878)$ & (434) & (761) & & \\
\hline
\end{tabular}

NOTE: Hobby, leisure and cultural associations are excluded from the analysis. ${ }^{*} p<0.05,{ }^{*} p<0.01,{ }^{* *} p<0.001$.

Table 2: Activists' embeddedness in private networks sensitive to the protest issue before joining Solidarity across borders (SAB), the Society for Threatened Peoples (STP), and Greenpeace (GP)

\begin{tabular}{|c|c|c|c|}
\hline & \multicolumn{3}{|c|}{ Activists from } \\
\hline & SAB & STP & GP \\
\hline Embeddedness and quality of ties & $\%$ & $\%$ & $\%$ \\
\hline No ties & 1 & 8 & 4 \\
\hline Only weak ties partly or highly sensitized & 1 & 1 & 1 \\
\hline Strong ties partly sensitized & 31 & 45 & 43 \\
\hline Strong ties highly sensitized & 66 & 45 & 52 \\
\hline $\begin{array}{r}\text { Total } \\
\mathrm{n}\end{array}$ & $\begin{array}{l}100 \% \\
(661)\end{array}$ & $\begin{array}{c}100 \% \\
(390)\end{array}$ & $\begin{array}{l}100 \% \\
(686)\end{array}$ \\
\hline Intensity of commitment (Cramer's V) & ns & - & ns \\
\hline
\end{tabular}

NOTE: ${ }^{*} p<0.05,{ }^{* *} p<0.01,{ }^{* * *} p<0.001$. 
Table 3: Activists' embeddedness in organizational and private networks before joining Solidarity across borders (SAB), the Society for Threatened Peoples (STP), and Greenpeace (GP)

\begin{tabular}{|c|c|c|c|}
\hline & \multicolumn{3}{|c|}{ Activists from } \\
\hline & SAB & STP & GP \\
\hline & $\%$ & $\%$ & $\%$ \\
\hline No networks & 0 & 3 & 2 \\
\hline Only organizational networks & 1 & 5 & 2 \\
\hline Only private networks & 11 & 37 & 58 \\
\hline Both organizational and private networks & 87 & 55 & 38 \\
\hline $\begin{array}{r}\text { Total } \\
\mathrm{n}\end{array}$ & $\begin{array}{l}100 \% \\
(661)\end{array}$ & $\begin{array}{c}100 \% \\
(390)\end{array}$ & $\begin{array}{l}100 \% \\
(686)\end{array}$ \\
\hline Intensity of commitment (Cramer's V) & $.26 * * *$ & - & $\mathrm{ns}$ \\
\hline
\end{tabular}

NOTE: For organizational networks, percentages are calculated from activists' embeddedness in prior networks that share master frames and boundary interpenetrations with their present protest, that is, postindustrial networks. ${ }^{*} p<0.05,{ }^{*} p<0.01,{ }^{* *} p<0.001$. 